Volume 3, Issue 1, February 2018, Pages: 246, DOI: http://dx.doi.org/10.19082/ah246

\title{
ANTHROPOGENETIC CHARACTERIZATION OF THE POPULATION OF BENI OUARSOUS IN THE TRARAS MOUNTAINS (ALGERIA) BY THE POLYMORPHISM OF BLOOD GROUPS (ABO, RHESUS, MNSS AND DUFFY): COMPARATIVE ANALYSIS ON A MEDITERRANEAN SCALE.
}

\author{
Djamel Belkhatir, amaria Aouar, Sarra Khater, Zakarya Moqaddem, Hoari Hamdaoui, Nafissa Chabni
}

Laboratoire de valorisation de l'action de l'homme pour la protection de l'environnement et application en santé publique (équipe environnement et santé), Faculté des Sciences, Université Abou Bekr Belkaïd de Tlemcen, Algérie djamelbelkhatir@yahoo.fr

\section{TYPE OF ARTICLE: CONFERENCE ABSTRACT}

\begin{abstract}
Background: The analysis of biological variability, long based on morphological and electrophoretic traits, extended to include blood polymorphisms that provide valuable information on the populations structure and history and the dynamics of their evolution. The objective of this work is the anthropogenetic characterization of the Beni Ouarsous population in the Traras Mountains in West Algeria.

Methods: The study was conducted by analyzing the blood groups (ABO, RH, MNSs and Duffy). The hemotypologic analysis focused on a sample of 200 individuals of both sexes.

Results: The obtained results show that the four systems are in genetic equilibrium (E.H.W). Analysis of total diversity shows that blood groups are intra-higher diversity, than diversity inter-area region. Comparative analysis through the principal components analysis and the phylogenetic trees shows the differences and similarities that exist between our population of Beni Ouarsous and populations from the two shores of the Mediterranean.

Conclusion: At the end of this analysis, we can say that our results are in agreement with other works, which suggest that the Algerian population is attached to the Berber ethnic groups, this is in spite of the multiple invasions in the north by the Phoenicians, the Romans, the Vandals, the Arabs and the French.

KEYWORDS: Beni Ouarsous, Algeria, Genetic affinity, Polymorphism, Blood markers, Anthropogenic
\end{abstract}

\footnotetext{
Abstracts of Second International Conference on Health Sciences and Medical Technologies, 10-12 October 2017, Tlemcen, Algeria (ICHSMT-17)

(C) 2018 The Authors. This is an open access article under the terms of the Creative Commons Attribution-NonCommercialNoDerivs License, which permits use and distribution in any medium, provided the original work is properly cited, the use is non-commercial and no modifications or adaptations are made.
} 